\title{
"Retrato de família": poema em preto e branco ${ }^{1}$
}

\author{
"Retrato de familia": a poem in black and white
}

2 Mestra e doutoranda em Letras - Estudos de Literatura pela Universidade Federal do Rio Grande do Sul (UFRGS). É autora do livro Móbile (Patuá, 2017), finalista do Prêmio Açorianos de Literatura

http://orcid.org/0000-0001-5970-959X

E-mail: oquefaltavaaopeixe@gmail.com

Recebido em: 26/12/2018

Aprovado em: 23/5/2019.

Publicado em: 16/12/201

\section{Endereço:}

Goncalves, 9500, Bairro Agronomia, Porto Alegre, RS, CEP: $91501-970$.
Ana Claudia Costa dos Santos ${ }^{2}$ Universidade Federal do Rio Grande do Sul, Programa de Pós-Graduação em Letras, Porto Alegre, RS, Brasil.

\section{RESUMO}

Este artigo relata o processo de criação do poema "Retrato de família", que integra minha dissertação de mestrado em Escrita Criativa. Além de comentar diversos detalhes da gênese do poema, sobretudo no que tange à tentativa de recriação de um retrato antigo, discuto as relações do texto em questão com a passagem do tempo, a epifania e a fotografia. Desse modo, o artigo busca contribuir não apenas para os estudos sobre a criação poética, mas também para a reflexão acerca do fértil diálogo entre diferentes técnicas ou artes - neste caso, entre a poesia e a fotografia.

Palavras-chave: Criação poética. Fotografia. Tempo. Epifania.

\section{ABSTRACT}

This article describes the creation process of a poem titled "Retrato de família”, which is part of my Creative Writing dissertation. Besides commenting on several details of the poem's genesis, especially with regard to the attempt to recreate an old portrait, I discuss how the poem relates to the passage of time, epiphany and photography. The article thus seeks to contribute not only to the study of poetic creation but also to the debate on the possible relations between different arts or techniques - poetry and photography, in this case.

Keywords: Poetic creation. Photography. Time. Epiphany.

"Fora os olhos dos retratos, ninguém sabe o que é a morte." (Adélia Prado, "Paixão")

Este artigo é uma adaptação do terceiro capítulo da dissertação intitulada Fabulário: criação poética e reflexão teórica, defendida em outubro de 2017 no Programa de Pós-Graduação em Letras da Universidade Federal do Rio Grande do Sul. A dissertação é composta por um conjunto inédito de poemas e três capítulos teóricos relacionados à obra. 


\section{Introdução}

$\mathrm{N}^{2}$

fase inicial de meu mestrado em Escrita Criativa, ainda em meio a muitas

dúvidas, surgiu o desejo de recriar uma fotografia em forma de poema. 0 assunto não é original: porque remetem tão eficazmente à passagem do tempo, os retratos figuram em um sem-número de textos poéticos ${ }^{3}$. Minha intenção, no entanto, era reproduzir o momento exato em que uma foto foi tirada, ou seja, reanimar, por meio da palavra, os seres retratados. Esse recurso deveria ser intensificado por sua antítese inevitável: a certeza da deterioração desses seres e do mundo que habitavam. Percebi então que, para obter o efeito pretendido, o poema deveria ser dividido em duas partes: 1) a descrição da fotografia em si; e 2) uma reflexão posterior do sujeito lírico sobre a fugacidade do momento capturado pelo fotógrafo (e, por extensão, sobre a transitoriedade da vida).

Eu teria, assim, dois olhares quase opostos: o primeiro registraria uma cena de maneira mais ou menos objetiva, ao passo que o segundo extrairia sentido dessa cena e deveria constituir, portanto, o ponto alto do poema. Aqui vale comentar outro objetivo do projeto original de minha dissertação de mestrado: enfatizar a relação entre experiência epifânica e experiência poética. Creio que o ciclo de um poema se completa apenas quando a epifania que lhe deu origem é transmitida ao leitor. Por esse viés, a atividade poética seria um constante esforço de catalogação de epifanias.

Naturalmente, o que relato aqui são meras aproximações. Afinal, os processos mentais que geraram "Retrato de família" ${ }^{4}$ se deram de modo caótico - como ocorre, suponho, na criação de qualquer trabalho artístico. Houve vaivéns, zigue-zagues, mudanças de rota. Apesar disso, é possível compartilhar com o leitor certos trechos do percurso. Este artigo está organizado em duas seções principais: na primeira delas, intitulada "Revelação", comento detalhes da gênese do poema5; na segunda, chamada "Negativos", exploro brevemente alguns temas presentes no texto e discuto aspectos da poesia em geral.

Em minha produção anterior, há outros poemas relacionados à fotografia. Destaco um deles, intitulado "Antes": "Nesta foto vive/ a infância de meu pai [...]/ Esse rosto sob seu rosto,/ a vida velha/ de tão nova, verde,/ pernas e braços compridos, / mal cabendo no quintal./ Sapatos limpos/ e franjinha penteada./Que sonhava meu pai/ ao sorrir para a foto/ antes da festa?" (SANTOS, 2017, p. 69-70).

O poema pode ser lido, como apêndice, no final deste artigo.

"Retrato de família" tem, ao todo, oito versões.

\section{Revelação}

No ensaio "Poesia e composição: a inspiração e o trabalho de arte", João Cabral de Melo Neto (1998) classifica os poetas em dois tipos: os que escrevem por inspiração e os que trabalham arduamente na construção de seus poemas; os que acham a poesia e os que a procuram. Embora eu considere essa cisão bastante radical e acredite em uma possível combinação desses dois tipos de processo, encaixo-me, ao que parece, na descrição dos poetas para quem a escrita é procura:

Nos poetas daquela família [...], existe como que o pudor de se referir aos momentos em que, diante do papel em branco, exercitam sua força. Porque eles sabem de que é feita essa força - é feita de mil fracassos, de truques de que ninguém deve saber, de concessões ao fácil, de soluções insatisfatórias, de aceitação resignada do pouco que se é capaz de conseguir e de renúncia ao que, de partida, se desejou conseguir (MELO NETO, 1998, p. 51, grifo nosso).

Foi assim com "Retrato de família”. Eu quis que o poema provocasse no leitor as sensações experimentadas ao observarmos uma fotografia antiga: ternura, melancolia, compaixão e, sobretudo, a consciência aguda de nossa finitude e da inexorabilidade do tempo. Tentei capturar um instante da vida de personagens alheios ao fim de sua própria história e, por isso mesmo, comoventes - como somos, afinal, todos nós. 0 resultado demonstra claramente essa busca, mas me parece incapaz de concretizar meu desejo original.

Além disso, como ocorre com esse grupo de poetas (no qual, ao que tudo indica, João Cabral de Melo Neto se inclui), minha escrita é "lacônica [...], lenta, avançando no terreno milímetro a milímetro" (MELO NETO, 1998, p. 65). Quando escrevi o primeiro rascunho de "Retrato de família", o título ${ }^{6}$ já havia surgido espontaneamente, mas as figuras foram despontando na página pouco a pouco: o avô, a avó, os tios, os primos, os pais, cada qual com sua ação respectiva.

Essa família, no entanto, não poderia ser a minha. Um dos desafios de meu projeto de Escrita Criativa consistia justamente em dar voz a diferentes sujeitos líricos: relatar lembranças inventadas, como a desse retrato. Sabe-se, porém,

6 Embora eu já conhecesse e admirasse o poema homônimo de Drummond, que integra A rosa do povo (1945), eu não o tinha em mente quando escolhi o título. Meses depois, percebi a coincidência. 
que é tênue a fronteira entre a experiência do autor e os elementos de sua obra, mesmo quando há um esforço deliberado de fabulação. Fragmentos de memórias, guardados há anos, emergem de súbito e se combinam para criar um pequeno mundo, estranho e íntimo a um só tempo. Nesse sentido, T. S. Eliot (1989, p. 44) afirma que "[a] mente do poeta é de fato um receptáculo destinado a capturar e armazenar um sem-número de sentimentos, frases, imagens, que ali permanecem até que todas as partículas capazes de se unir para formar um novo composto estejam presentes juntas". Ainda segundo Eliot (1989, p. 44), "o que conta não é a 'grandeza', a intensidade, das emoções, dos componentes, mas a intensidade do processo artístico, a pressão, por assim dizer, sob a qual ocorre a fusão".

Figura 1 - Anotações para a escrita do poema "Retrato de família” (maio de 2016)

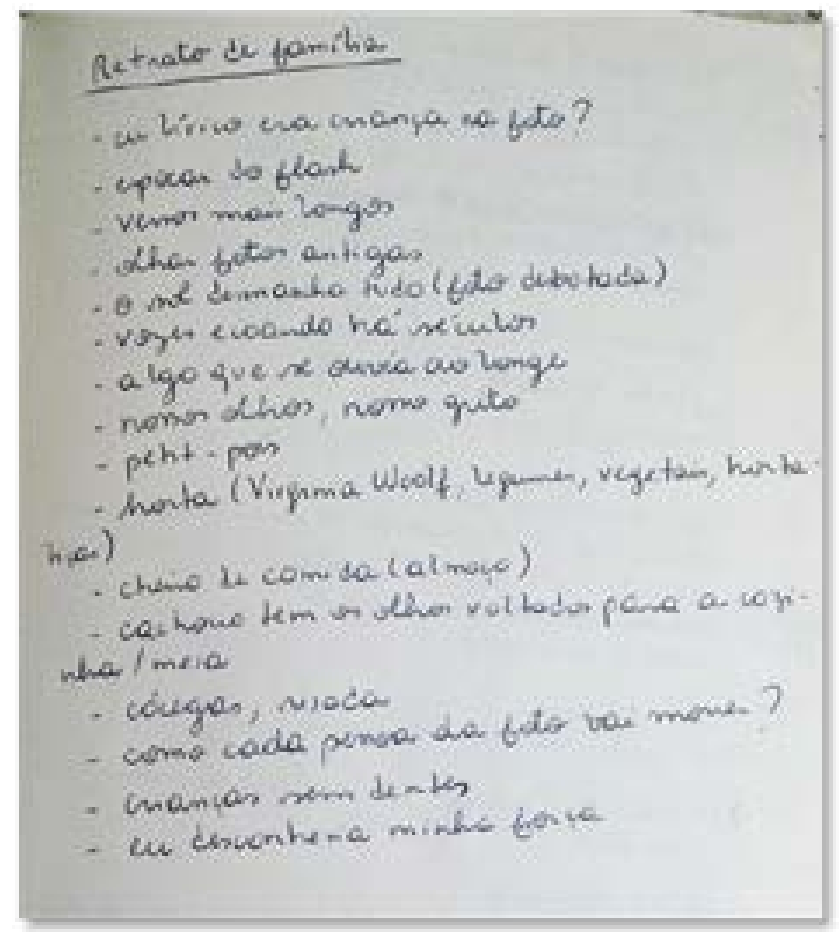

Fonte: Acervo da autora
Os componentes do poema ecoam, portanto, meu repertório de lembranças, mesmo se tento fugir delas: 0 avô que finge ler, a avó que cultiva flores, o pai que me leva nas costas etc. 0 que ocorre é um "ajuste" do real a fim de intensificar o efeito da obra. Por isso, apesar de minha avó paterna ter declarado, na verdade, que "o sol desmancha tudo", para a avó de "Retrato de família", o signo associado à destruição é o breu. Somente ao trabalhar na sétima versão do texto percebi que essa alteração era imprescindível para seu desfecho. Sem ela, a oposição "luz versus escuridão" - um tanto óbvia, talvez, mas inerente ao tema - não funcionaria, prolongando minha busca por um final adequado para o poema.

Algumas mudanças definitivas foram feitas já na transição entre a segunda e a terceira versão do texto. A troca de nomes brasileiros por nomes germânicos, por exemplo, foi a maneira que encontrei de distanciar-me da família retratada, tornando-a "estranha" (segundo a proposta da constituição de sujeitos líricos diversos). Ademais, influenciada pela recente leitura do trabalho da alemã Nora Bossong 7 , pensei que talvez os nomes estrangeiros pudessem conferir ao poema certo caráter mítico. Para ilustrar o que digo, apresento abaixo a segunda versão da primeira parte do texto:

Versão 2, parte 1

O avô finge ler As mil e uma noites, um volume pesado e púrpura, que ele traz aos olhos iletrados. Só entende o cabelo da avó, papel branco de que nasce um girassol, pendendo para o leste.

Na cadeira de balanço, tia Clara come chocolates, os papéis coloridos sobre ventre e pernas: uma rainha em seu trono.

Traduções para o português de poemas de Nora Bossong podem ser encontradas na edição 189 do Rascunho: BOSSONG, Nora. Poemas de Nora Bossong. Tradução de Viviane de Santana Paulo. Jornal Rascunho, Curitiba, ed. 189, fev. 2016. Disponível em: http://rascunho.com.br/24077-2. Acesso em: 26 dez. 2018. 
Pedrinho belisca Alice, cobiçando-lhe as asas

de frango. Ela chora. Ao seu lado, Bilu espera os ossos.

Anáguas secam no varal. Tio Antônio exibe

ameixas recém-colhidas. Meu pai me leva nas costas,

não me deixa cair. A luz recorta e guarda

o riso de minha mãe.

Além dos nomes dos membros da família, as diferenças entre essa versão e o texto final são evidentes. Em primeiro lugar, ela é tecnicamente inferior: contém problemas de ritmo e sonoridade, bem como alguns excessos. São detalhes sutis, percebidos de modo intuitivo. Observe-se a metáfora canhestra da estrofe inicial, por exemplo: "[...] Só entende o cabelo/ da avó, papel branco de que nasce/ um girassol [...]". Na última versão, a figura da avó ganha autonomia e força poética: “[...] Girassóis nascem/ das mãos da avó [...]”. Algo semelhante ocorre no quinto verso da segunda estrofe: desagradavam-me a irrelevância do choro de Alice e a obviedade da espera de Bilu. As alterações foram mínimas (o verso foi dividido, o cão perdeu o nome e os ossos ganharam um adjetivo), mas atenuaram minha insatisfação: “[...] entre os dois, o cão espera/ os ossos novos”.

Há ainda a troca do livro que o avô finge ler - de As mil e uma noites, título que evoca imagens do Oriente, para contos de fadas em geral, mais facilmente relacionáveis ao universo do poema - e diversas outras substituições: "traz aos olhos" por "aproxima dos olhos", "pendendo" por "virados", "cadeira de balanço" por "cadeira de vime", "chocolates" por "doces", "belisca" por "puxa as tranças de", "anáguas" por "saias".

As "ameixas recém-colhidas" são um caso à parte. Minha intenção original era substituí-las por figos (devido à carga simbólica do fruto), mas essa escolha implicaria a difícil tarefa de fazer tombar uma figueira na segunda seção do poema. Optei então pelas amoras e associei a elas sapatos de verniz, em contraste com os pés descalços do pai. Quanto ao "riso de minha mãe", eu o teria deixado intacto, não fosse a necessidade de reforçar os sorrisos de todos os personagens no instante em que posaram para a foto: "Sorríamos, e a noite maior/ já se formava (o fim de cada um/ vedado aos sais de prata)".
A propósito, a elaboração do trecho final do poema foi particularmente trabalhosa. Eu precisava criar um desfecho que reproduzisse a oposição entre a cena gravada no retrato e tudo o que viria depois: a decadência do espaço físico e o envelhecimento ou a morte dos personagens. Ainda que eu me identifique, como mencionei anteriormente, com os "poetas intelectuais" de que fala João Cabral de Melo Neto, escrevo sempre na tentativa de registrar alguma percepção dolorosa e súbita. Em meio à feitura do poema, dei-me conta de que ele deveria expressar não a inevitabilidade da morte, mas a permanência da vida: o fato de que, por um segundo, os membros daquela família compartilharam um pedaço da eternidade. Por ser a matéria-prima da fotografia, a luz deveria desempenhar um papel central nesse esquema. 0 problema era como expor essa percepção, sobretudo levando-se em conta a excessiva concisão de meu estilo.

A ideia inicial para a segunda seção do poema era dizer claramente qual seria o fim de cada um dos personagens. Observe-se o primeiro esboço:

Versão 1, parte 2

"O sol desmancha tudo", disse vovó

naquela manhã; desmanchou também

aquela manhã. 0 espocar de luz

não parou o tempo. Os velhos sucumbiram

ao coração; tia Clara, ao estômago. Cego, Bilu

saiu sem rumo. Tio Manoel seguiu o exemplo.

Mário e Isabel padecem do azedume

que balas não adoçam. Quanto a mim, tenho caído

amiúde, sem leveza alguma. ${ }^{8}$

Logo percebi as limitações dessa ideia. Não importava o que aconteceria a cada uma das figuras da foto, pois elas eram somente imagens sem concretude. Meu trabalho consistiria, portanto, em traçar esses destinos de maneira abstrata, relacionando, direta ou indiretamente, os elementos do segundo segmento do poema aos do primeiro. As duas primeiras estrofes da seção final tomaram forma

8 Alguns nomes foram trocados na transição entre a versão 1 e a versão 2. 
já a partir da terceira versão (com uma ou outra alteração pontual); a dificuldade residia, assim, nas três últimas estrofes. Que objetos seriam encontrados na escavação imaginária do quintal? Como dispor as palavras de modo a fechar o texto em chave epifânica? É interessante observar a evolução das estrofes mencionadas:

\section{Versão 4, parte 2}

Se alguém escavasse o quintal

da infância, veria ossos de aves

e de cães, uns cadarços terrosos,

vozes e chávenas quebradas.

(Os mortos não sabem sua força, a vida que imprimem nos retratos.)

À noite cantamos e dormimos, incautos...

Versão 5, parte 2

Se alguém escavasse

o quintal da infância, acharia ossos

de aves e cães, uns cadarços terrosos,

ecos: "Não vá soltar a menina!

Onde estão suas sandálias?".

Os mortos ignoram sua força,

a vida que imprimem nos retratos.

Enquanto piscamos, o fim

de cada um queimou os sais de prata;

e seguimos, incautos...
Versão 6, parte 2

Se alguém escavasse

o quintal da infância, veria ossos

de aves e cães, uns cadarços

terrosos, anéis, a família bordada

na toalha de mesa.

(Os mortos ignoram sua força,

a vida que gravam nos retratos.)

Piscávamos, e a noite

maior já se formava, o fim de cada um

vedado aos sais de prata.

Incautos, partimos

nessa viagem na luz.

Versão 7, parte 2

Se alguém escavasse

o quintal antigo, acharia ossos

de aves e cães, uns cadarços

terrosos, o cetim desfeito

de laços de fita.

Os mortos ignoram sua força

a vida que gravam nos retratos.

Porque a noite maior

já se formava (o fim de cada um

vedado aos sais de prata), reluzimos

como sóis. 


\section{Versão 8, parte 2}

\section{(Se alguém escavasse}

o quintal da infância, acharia ossos

de aves e cães, uns brinquedos

terrosos, o corpo desfeito

de um fantoche antigo.)

Os mortos ignoram sua força,

a vida que gravam nos retratos.

Sorríamos, e a noite maior

já se formava (o fim de cada um

vedado aos sais de prata):

em pleno ocaso, reluzimos

mais que sóis.

Oscilei, por exemplo, entre "o quintal da infância" e "o quintal antigo", optando enfim pelo primeiro e relacionando os objetos desenterrados às crianças da foto. Os "brinquedos terrosos" substituíram os insistentes "cadarços terrosos" (ligados frouxamente aos sapatos de verniz da primeira seção). 0 velho fantoche, por sua vez, confere graça à estrofe e deve ter vindo da lembrança de uma família alemã que conheci - recordo os fantoches de reis, rainhas e fadas costurados pela avó. Pensei inicialmente em objetos imateriais ("vozes", "ecos"), mas decidi rejeitá-los nas próximas versões a fim de não exagerar na dose de abstração. Afinal, conforme ensina Italo Calvino (1990, p. 28), a leveza desejada na escrita literária "está associada à precisão e à determinação, nunca ao que é vago ou aleatório". Há também mudanças na divisão de versos e estrofes, bem como pequenas alterações na construção de frases, troca de verbos - "veria" por "acharia", "não sabem" por "ignoram", "imprimem" por "gravam" - e variações no uso de parênteses para isolar trechos do texto. Em todas as versões, no entanto, percebe-se o uso de enjambements, ou seja, a não coincidência entre verso e "grupo de força" - definido por Britto (2011, p. 6) como "a porção de texto que se costuma ler em voz alta sem pausa".
Figura 2 - Rascunhos e anotações referentes à segunda parte do poema "Retrato de família" (junho de 2016)

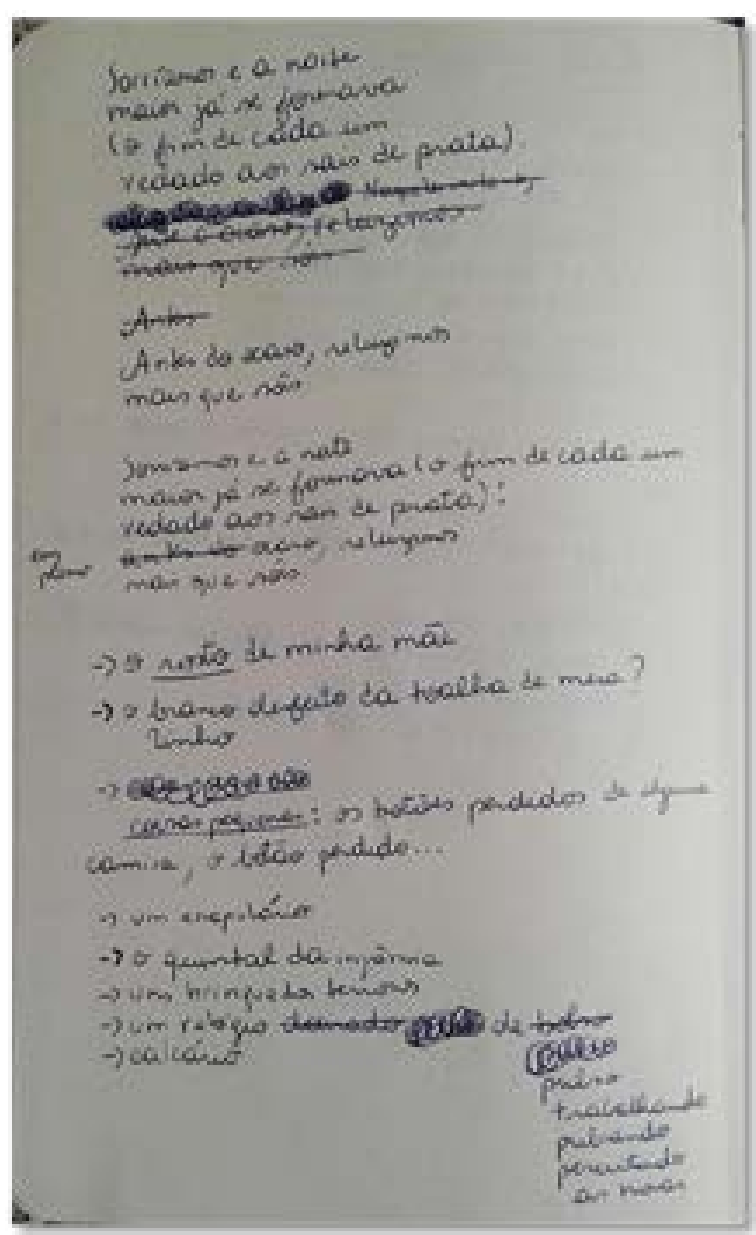

Fonte: Acervo da autora. 
Por fim, busquei um desfecho que sintetizasse a essência do poema. 0 sal de prata, como se sabe, é uma substância presente nos filmes fotográficos que, quando exposta à luz, forma as imagens no negativo. Na quinta versão, a certeza e o mistério da morte brilham tão intensamente que chegam a "queimar" essa substância. Em seguida, ocorreu-me a noção da "noite maior" (a morte) em oposição à natureza luminosa da fotografia e da vida. Sendo escura, essa noite não afetaria os sais de prata e, portanto, estaria oculta na imagem. Alheios ao ocaso ("incautos", como eu queria qualificá-los), os personagens, entre os quais se inclui o sujeito lírico, por um instante reluzem "mais que sóis". Além de o sol ser o símbolo da luz por excelência, há aí a feliz semelhança sonora entre "sóis" e "sais", o que talvez contrarie a máxima citada por Umberto Eco (1985, p. 22) em seu Pós-escrito a O Nome da Rosa: "[na poesia,] verba tene, res sequentur". Pelo menos neste caso específico, as palavras foram consequência das coisas.

\section{Negativos}

Para citar mais uma vez o poeta-engenheiro, "[hoje] em dia é impossível determinar até onde deve ir a elaboração do poema. Onde interrompê-la. É possível fazê-la prolongar-se indefinidamente" (MELO NETO, 1998, p. 66). 0 autor refere-se à liberdade formal da poesia moderna e à ausência de parâmetros para a escrita de um texto poético. Em que ponto de sua elaboração um poema em verso livre pode ser considerado pronto? Para mim, isso ocorre quando tenho a sensação de que as palavras finalmente "assentaram" na página, quando a inquietação inicial se extingue e tudo parece estar onde deveria estar.

Essa sensação, entretanto, nada tem a ver com plenitude: ela está atrelada à consciência não apenas de minhas limitações como poeta, mas também das limitações da própria linguagem. Sobre o assunto, Italo Calvino (1990, p. 88, grifo do autor) declara que, "ao se dar conta da densidade e da continuidade do mundo que nos rodeia, a linguagem se revela lacunosa, fragmentária, diz sempre algo menos com respeito à totalidade do experimentável". Nesse sentido, "[a] palavra associa o traço visível à coisa invisível, à coisa ausente, à coisa desejada ou temida, como uma frágil passarela improvisada sobre o abismo" (CALVINO, 1990, p. 90). Escrever - e, sobretudo, escrever poesia - é atravessar esse abismo ou, na maioria das vezes, deixar-se cair nele.
Octavio Paz (2012) afirma que as origens e o fim da poesia se confundem com os da linguagem, frisando que o ritmo, entendido como temporalidade concreta, é o que diferencia o verso da prosa. Para o autor, o poema "se oferece como um círculo ou uma esfera: algo que se fecha sobre si mesmo, universo autossuficiente cujo final é também um princípio que volta, se repete e se recria. E essa constante repetiçãorecriação não passa de ritmo, maré que vai e vem, sobe e desce" (PAZ, 2012, p. 75).

Desse modo, a poesia estaria irremediavelmente ligada ao tempo. Em um ciclo perpétuo, os personagens de "Retrato de família" revivem a cada leitura do poema: animados pelo ritmo das palavras, eles deixam o recanto escuro em que se escondem para, mais uma vez, reunirem-se sob o sol daquela manhã. Jorge Luis Borges (1999, p. 239) observa o seguinte:

Sentimos que estamos deslizando pelo tempo, ou seja, podemos pensar que passamos do futuro ao passado, ou do passado ao futuro, mas não há um instante em que possamos dizer ao tempo: "Pára! És tão belo!...", como queria Goethe. 0 presente não se detém. Não poderíamos imaginar um presente puro; seria nulo. 0 presente tem sempre uma partícula de passado, uma partícula de futuro. E parece que isso é necessário ao tempo.

A poesia e a fotografia desafiam essa verdade. Nessas duas linguagens, o presente se detém, repleto de horror ou beleza, e pode repetir-se ad infinitum: um redemoinho estático e eterno. Também a experiência epifânica é capaz de interromper o fluxo do tempo e, por isso, considero-a requisito básico para a criação artística. Para mim, só é possível escrever a partir desse sentimento bruto, ainda que se passem dias, semanas ou meses até que eu consiga lapidá-lo.

De acordo com Yudith Rosenbaum (1999, p. 135), a epifania literária consiste na "percepção de uma inusitada revelação, de uma realidade atordoante, em meio aos gestos mais banais, à mais simples e rotineira experiência". Em "Retrato de família", busquei reproduzir a insuportável ternura (na falta de um termo mais preciso) que me acomete ao ver famílias posando para fotos. Essa ternura desencadeia uma torrente de pensamentos muito lúcidos, enunciáveis apenas por meio da linguagem poética.

Além de Nora Bossong, outros poetas me acompanharam ao longo do processo de criação. A influência de Jorge de Lima, por exemplo, é evidente na primeira estrofe. Assim começa o poema 25 de Anunciação e encontro de Mira-Celi: 
O avô tinha sido um ancião convencional,

que se enterrou de sobrecasaca e polainas;

e a avó - uma menina pálida que morreu ao pari-la;

o pai fez algumas baladas;

contam que tinha uma luneta para olhar ao longe.

(LIMA, 2014, p. 145).

Trata-se de episódios da história de uma família contados por meio de um álbum de fotos. A peculiaridade da descrição dos personagens e a riqueza das imagens fixaram-se em minha mente desde a primeira vez que li o poema. Quando me propus a descrever um retrato, a sombra do álbum de Jorge de Lima projetou-se imediatamente sobre a página. Talvez por isso eu tenha optado por usar "o avô" e "a avó", e não "vovô" e "vovó", embora o sujeito lírico faça parte da família. Outro motivo para essa escolha foi a ideia de uma aproximação gradual das figuras: a primeira seção do poema fica mais pessoal à medida que se encaminha para o fim.

Já na escrita da segunda seção, a influência principal foi a poesia de Ruy Espinheira Filho. Um dos temas predominantes na obra do poeta baiano é o desamparo do homem diante da passagem do tempo. Eu desejava exprimir esse desamparo em "Retrato de família". 0 seguinte fragmento do poema "Aqui, antes da noite" exemplifica-o bem:

Sei: com o tempo

só os mortos sobrevivem.

$[\ldots]$

Vem uma brisa cheia de asas e polens

e barcos de brinquedo

no laguinho da praça.

Uma brisa de mim,

de quando tudo estava ainda por vir. E não viria, não, como veio.

Viria luminoso e bom. Viria imensamente

luminoso e bom. Como não veio.

(ESPINHEIRA FILHO, 2012, p. 90-91).

Devo citar, ainda, o trabalho do poeta americano Gregory Orr, um mestre na escrita de textos concisos e cheios de lirismo. 0 desejo de criar uma escavação hipotética consolidou-se após a leitura do seguinte trecho do poema "The excavation":

Sua viagem para o outro mundo

podemos deduzir pelo modo

como um esqueleto está posto

num túmulo, mas aqui

é onde viveram

e sinais de vida

é o que vamos encontrar ${ }^{9}$.

(ORR, 2002, p. 41, tradução nossa).

Eu me baseava em uma noção similar à apresentada por Orr, no sentido de que deveriam ser valorizados vestígios da vida - e não da morte ou decadência - daquela família.

Embora eu acredite que um poeta pode afirmar-se apenas quando encontra sua própria voz, essas influências não chegam a ser fonte de aflição. Vejo-as como parte natural do processo, e assim também as via Umberto Eco (1985, p. 40), que fala do "diálogo entre o texto e todos os outros textos escritos antes", ressaltando que "só se fazem livros sobre outros livros e em torno de outros livros".

Do original: Their journey to the other world/ we might infer from the way/ a skeleton's arranged/ in a grave, but this/ is where they lived/ and signs of life/ are what we'll find. 


\section{Considerações finais}

Como sugeri anteriormente, relatar a gênese de um poema é procurar sentido no caos. Afinal, é também por meio de palavras que se opera a tentativa de rastrear o percurso até o texto poético - e as palavras, como se sabe, são fugidias. Por mais que eu me esforce para ser fiel aos fatos, há sempre algo que me escapa: sinto que estou fabricando "a representação de uma representação" e que, com isso, me afasto da experiência concreta.

Creio que a melhor explicação de uma obra só pode ser a própria obra, com sua linguagem e seus recursos específicos. A criação poética é um enigma que, a meu ver, deve permanecer indecifrável, pois é aí que reside seu fascínio. Ainda que eu considere fundamentais o domínio da técnica e a valorização do processo criativo, gosto de pensar que também estou lidando com magia - se a vida tem um significado oculto, ele se manifesta por meio da arte e, em especial, por meio da poesia.

Dito isso, as versões de "Retrato de família" são etapas essenciais de sua concepção e permitem visualizar meu raciocínio, mesmo que seja difícil recuperar totalmente a pré-seleção mental e as anotações que fiz antes de escrever cada rascunho. Refletir sobre a arte poética é especialmente relevante em dias como os nossos, em que, por vezes, se usa o termo "poesia" de forma leviana.

\section{REFERÊNCIAS}

BORGES, Jorge Luis. 0 tempo. In: BORGES, Jorge Luis. Obras completas IV. Tradução de Josely Vianna Baptista, Maria Rosinda Ramos da Silva e Sérgio Molina. São Paulo: Editora Globo, 1999. p. 231-240.

BRITTO, Paulo Henriques. Para uma tipologia do verso livre em português e inglês. Revista Brasileira de Literatura Comparada, n. 19, p. 127-144, 2011.

CALVINO, Italo. Seis propostas para o próximo milênio. Tradução de Ivo Barroso. São Paulo: Companhia das Letras, 1990.

ECO, Umberto. Pós-escrito a O Nome da Rosa. Tradução de Letizia Zini Antunes e Álvaro Lorencini. Rio de Janeiro: Nova Fronteira, 1985.
ELIOT, Thomas Stearns. Tradição e talento individual. In: ELIOT, Thomas Stearns. Ensaios. Tradução, introdução e notas de Ivan Junqueira. São Paulo: Art Editora, 1989. p. 37-48.

ESPINHEIRA FILHO, Ruy. Estação infinita e outras estações. Rio de Janeiro: Bertrand Brasil, 2012. LIMA, Jorge de. Antologia poética. São Paulo: Cosac Naify, 2014.

MELO NETO, João Cabral de. Poesia e composição: a inspiração e o trabalho de arte. In: MELO NETO, João Cabral de. Prosa. Rio de Janeiro: Nova Fronteira, 1998. p. 51-70.

ORR, Gregory. The caged owl. Port Townsend: Copper Canyon Press, 2002.

PAZ, Octavio. O arco e a lira. Tradução de Ari Roitman e Paulina Wacht. São Paulo: Cosac Naify, 2012.

ROSENBAUM, Yudith. Poesia, sonho e psicanálise: a palavra em estado de encantamento. Psicanálise e universidade, São Paulo, n. 11, p. 121-143, jul./dez. 1999.

SANTOS, Ana. Móbile. São Paulo: Patuá, 2017.

\section{Apêndice}

\section{Retrato de família}

0 avô finge ler contos de fadas,

um volume pesado e púrpura

que ele aproxima

dos olhos iletrados. Girassóis nascem

das mãos da avó, virados para o leste.

Na cadeira de vime, tia Sybille come

doces, os papéis coloridos

sobre ventre e pernas: uma rainha 
em seu trono. Anton puxa as tranças de Johanna, cobiçando-lhe as asas de frango; entre os dois, o cão espera os ossos novos.

Saias secam no varal. Uma libélula invade a cena. Tio Otto exibe amoras e sapatos de verniz. Descalço, meu pai me leva nas costas, não me deixa cair. A luz recorta e guarda o rosto de minha mãe.

$* * *$

"O breu consome tudo", disse a avó naquela manhã; consumiu também aquela manhã. 0 açúcar não adoça a língua amarga do tempo.

Num poço fundo, afogam-se as fadas dos contos. Tombadas casa e amoreira, nada resta nesse chão de ervas daninhas.

(Se alguém escavasse

o quintal da infância, acharia ossos de aves e cães, uns brinquedos terrosos, o corpo desfeito de um fantoche antigo.)

Os mortos ignoram sua força, a vida que gravam nos retratos. Sorríamos, e a noite maior já se formava (o fim de cada um vedado aos sais de prata):

em pleno ocaso, reluzimos mais que sóis. 